\title{
BILATERAL INTERPRETING COURSE IN BLENDED LEARNING: EXPERIMENTAL VERIFICATION
}

\author{
Svitlana Kolomieets \\ National Technical University of Ukraine "Igor Sikorsky Kyiv Polytechnic Institute", \\ Kyiv, Ukraine \\ svitlanak29@gmail.com \\ Lyudmyla Guryeyeva \\ National Technical University of Ukraine "Igor Sikorsky Kyiv Polytechnic Institute", \\ Kyiv, Ukraine \\ ludmila.goureyeva@gmail.com
}

\begin{abstract}
The paper presents the research on the effectiveness of blended learning within the designed Moodle-based course of bilateral interpreting using interdisciplinary terminology. The authors analyse modern educational technologies and prospects for future professionals in the context of bilateral interpreting. The research reveals the outcomes of the experimental study conducted at the National Technical University of Ukraine "Igor Sikorsky Kyiv Polytechnic Institute" involving the students at the final stage of the bachelor's degree programme proving the efficiency of modern approach based on blended learning concept. The study also proves the fact that integration of blended learning courses can help future professionals develop skills such as critical thinking, problem solving, agility and adaptability, initiative and entrepreneurialism, effective oral and written communication, accessing and analysing information that are considered to be critically important for the twenty-first century. The detailed analysis of modern scientific literature proves that modern information technologies and blended learning, in particular, become an integral part of today's educational tendencies both in Ukraine and abroad, offering a wide range of possibilities for students.
\end{abstract}

Keywords: blended learning; bilateral interpreting; e-learning; mediation; interdisciplinary approach; interdisciplinary terminology.

\section{Introduction}

The international cooperation and integration of Ukraine into the global community makes the role of interpreting extremely important. The rapid development of modern science and technology opens up an infinite number of means of information transmission, and an interpreter plays a key role in this process. Due to such developments, the role of interpretation as a means of mediation in communication and support of economic, social, political and scientific relations between different countries is increasing significantly.

In the updated descriptors of the Common European Framework of Reference for Languages mediation includes spoken interpretation and written translation (Section 4), stressing the importance of this type of activity in the educational context (Brian North, 2016).

Recently, the role of educators has changed greatly. They do not just deliver knowledge anymore, but they help students to organise their learning process in the most productive, efficient and the most effortsaving manner (Tarnopolsky, 2012). The expansion of modern technologies not only facilitates the process of learning, but it also changes the attitude to knowledge and learning, introducing new educational concepts such as blended learning (Huber, 2014). Blended learning combines two archetypal learning environments - the traditional face-to-face and distance learning (Bonk, 2007). According to the definition of Sloan Consortium, blended courses are defined as having between 30 per cent and 79 per cent of the course content delivered online (Elaine Allen, 2007). Tarnopolsky (2012) defines blended learning "as a synergic learning structure, dynamically and organically combining into an indivisible unity traditional classroom learning with online learning for creating a more flexible learning environment with the purpose of intensifying and facilitating the practical training process" (p. 14). This technology gives greater opportunities not only to students, allowing controlling their educational process and offering various correction strategies (Hoyos, 2018), but also to institutions, giving a number of options in how they can choose to structure a blended course. Welzer (2018) notes that technology-enhanced education offered new types of learners as well as the potential to suggest resources to other institutions, meaning the learners could use blended learning strategy choosing when and where they learn. Blending not only the amount of time spent in classroom or on-line but also the structural components of the course at different levels (activity level, course level, programme level) offers a wide range of educational prospects. Now blended learning appears to be the most suitable mode for teaching translating and interpreting. In the regard of a methodological system for teaching interpreting, the latest works of Zinukova (2018) and Volodko (2017), are of particular interest.

Cynthia Luna Scott presenting UNESCO Working Papers (Scott, 2016), mentions in her recent report (p. 3), that Wagner (2010) and the Change Leadership Group at Harvard University identify "a set of 
competencies and skills that students need to be prepared for twenty-first century life work and citizenship" (p. 4). They mention critical thinking and problem solving, agility and adaptability, initiative and entrepreneurialism, effective oral and written communication, accessing and analysing information (Scott, 2016). We think blended learning helps to develop the abovementioned key competences and skills facilitating the shift from traditional classroom activities to astudent-centred mode of studying.

The ultimate goal of blended learning is to increase the effectiveness of learning by systematically evaluating interdependent variables and integrating learning tools. Webinars (interactive audio and video online classes) allow students and teachers to communicate in a suitable manner, replacing traditional classroom environment within the frame of a bilateral interpreting course, especially given the fact that the leading educational institutions of Ukraine have all the capabilities for implementing blended learning, greatly increase the effectiveness of the educational outcomes. However, Dooly \& Sadler (2016) state, that "while it has almost become a cliché to emphasise the necessity of integrating technology into language teaching in today's society, how to do so still remains a pending issue" (p. 73).

The aim of the research is to assess the effectiveness of the blended learning mode within the bilateral interpreting course. To achieve the aim, the following objectives were set: to design a blended Moodle-based course to practice bilateral interpreting, conduct an experiment and interpret its results.

\section{Method}

In order to develop the Moodle-based course, the following scientific methods were applied: the modelling of the educational process within the concept of the blended learning; the critical analysis of the modern scientific and pedagogical sources; the processing of the data obtained using mathematical statistics methods; anonymous surveys as the tools used in qualitative research to learn about students' and teachers' perceptions of the material (Ward, 2018); and organising and conducting an experiment to verify the effectiveness of the developed methodology.

Therefore, the relevance of the research is based on the needs to train bilateral interpreting professionals within the blended learning mode. The abovementioned course was designed applying Moodle platform (Guryeyeva, 2016).

Participants. The experiment was conducted at the National Technical University of Ukraine "Igor Sikorsky Kyiv Polytechnic Institute" involving the students at the final stage of the bachelor's degree programme. 68 students took part in the experiment. It was the optimum number of students calculated using the mathematical statistics method so that the maximum permissible error does not exceed 3\% (Gmurman, 2004).

The designed course (20 hours) blends online and face-to-face delivery: 8 hours of in-class activities and 12 hours of students' practice using on-line Moodle platform.

Materials. The terminology used as teaching materials has an interdisciplinary focus on power engineering, ecology, physics, chemistry, and mathematics (1500 terms and term collocations). The main criteria for the lexical material selection were the following: semantic value, semantic connectivity, thematic attribution, and word frequency, following the model suggested by Buchbinder (1986). It also includes authentic audio recordings of conversations, exercises for training bilateral interpreting interdisciplinary terminology and instructional guidelines. The course consists of three main parts. The first one enables students to identify their level of knowledge and further develop their psychophysiological mechanisms such as memory capacity, reaction speed, concentration skills as well as their listening skills. The second set of exercises allows students to improve their lexical and grammatical skills to form their ability to interpret using interdisciplinary polysemantic terms and narrow-domain terms as well as practice code-switching within the context of bilateral interpreting. The third one allows students to practice their bilateral interpreting skills.

Procedure. The procedure of the experiment is described below in further detail. The experimental training included the following stages: 1) experiment organisation and a pre-test; 2) experiment implementation (two series of experimental training); and 3) a post-test and interpretation of the data obtained. The main purpose of the experiment was to test the effectiveness of the designed e-learning bilateral interpreting course based on interdisciplinary terminology.

Two focus groups passed a pre-test with similar content during the first experimental phase. The results helped identify the statistical and psychophysiological performance of the participants (Figure 1). The students could score from 1 to 4 . As it can be seen, the participants of both groups scored approximately similar marks. The average score of focus group 1 FG1 is 2.01 and of FG2 is 1.98 . 


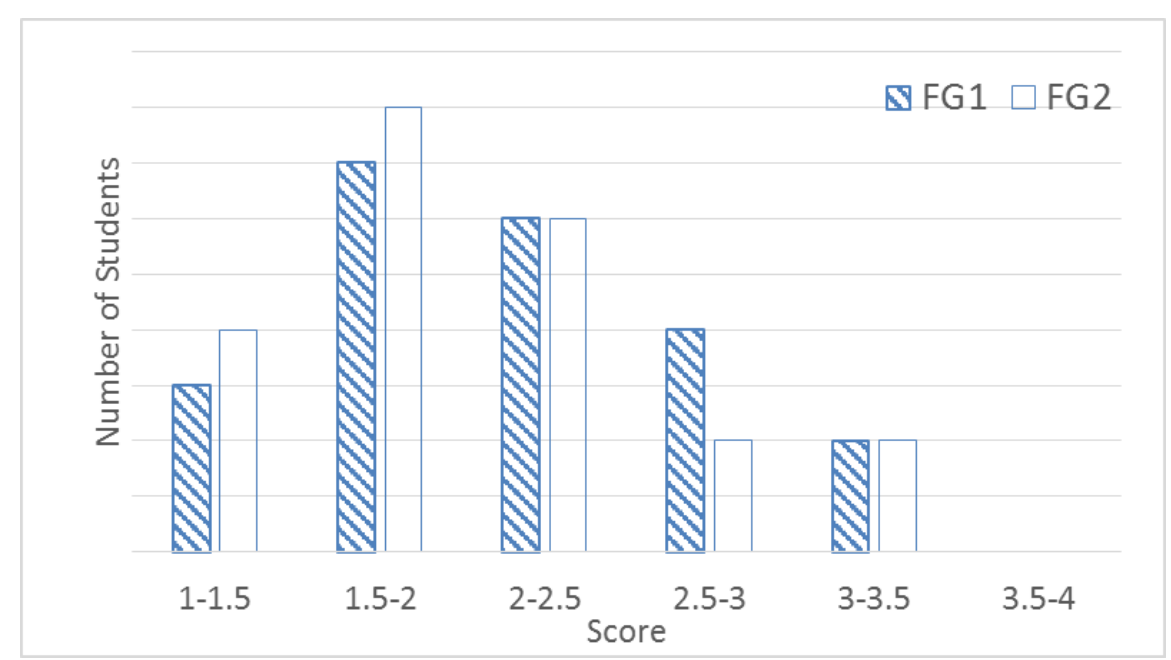

Figure 1. Pre-test results: FG1 - focus group 1, FG2 - focus group 2

During the second experimental phase, the same focus groups participated in the main part of the experiment developing their listening skills, lexical competence, and code-switching skills as well as interpreting skills. Both groups of the participants had tests with similar content; however, the first focus group FG1 did not have set time limits and worked at their own pace. The second group FG2 had limited time to perform the tests imitating the process of bilateral interpreting. At the beginning and at the end of every working session the participants passed the State-Trait Anxiety Inventory (STAI, б.д.), initially created by Spielberger (1983), developed to access person's state and trait anxiety. The inventory consists of 20 questions to assess state anxiety, and another 20 questions to assess trait anxiety allowing checking a person's state after passing the tests to help students check the development of their psychophysiological mechanisms.

The third experimental phase was a post-test to measure students' achievement and the effectiveness of the developed course as well as the interpretation of the results.

\section{Results}

The aim of the research was to assess the effectiveness of the blended learning mode within the bilateral interpreting course by designing a blended Moodle-based course to practice bilateral interpreting, as well as conducting an experiment and interpreting its results.

As mentioned above, two focus groups (FG) took part in the experiment practicing bilateral interpreting using interdisciplinary terminology. Both groups, FG1 and FG2, had the same tasks and the unlimited number of attempts. However, FG2 had limited time to perform the tasks imitating stressful conditions of real bilateral interpreting process. Moreover, under certain circumstances, it might be a challenge to control participants' access to computer and Internet tools during the tests (Monteiro, 2014). From this perspective, time limitation helps reduce this issue.

The results of the experiment proved that both groups have improved their performance (Figure 2 and Figure 3). The maximum score was 4. Compared to the results shown in Figure 1, the participants of both groups showed better results. Moreover, the bigger number of the participants scored the result higher than 2.5.

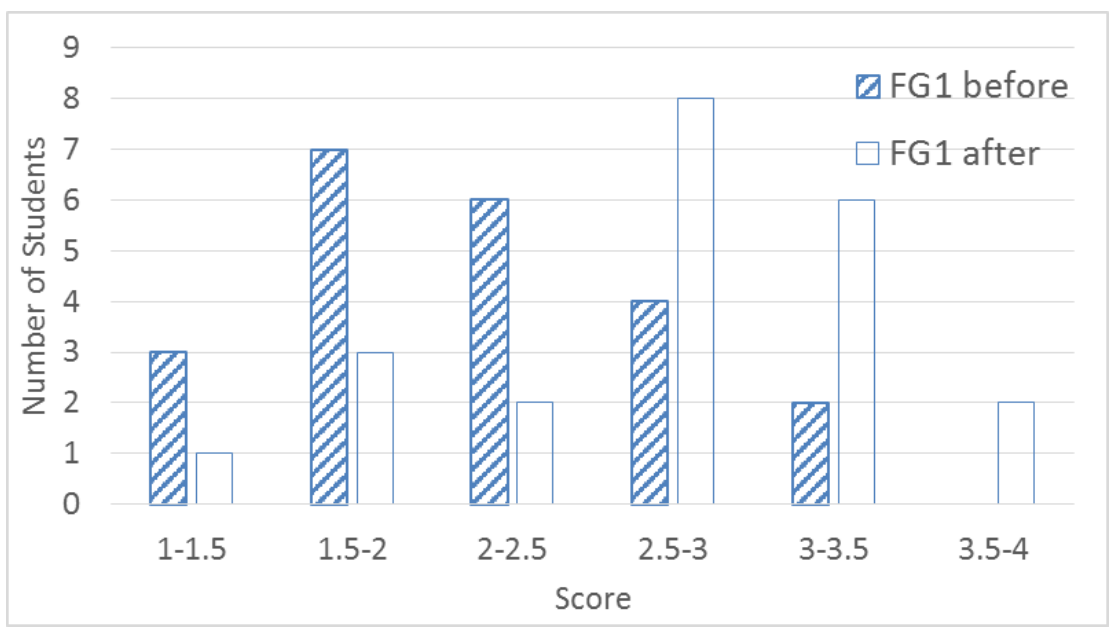

Figure 2. Test results of FG1 


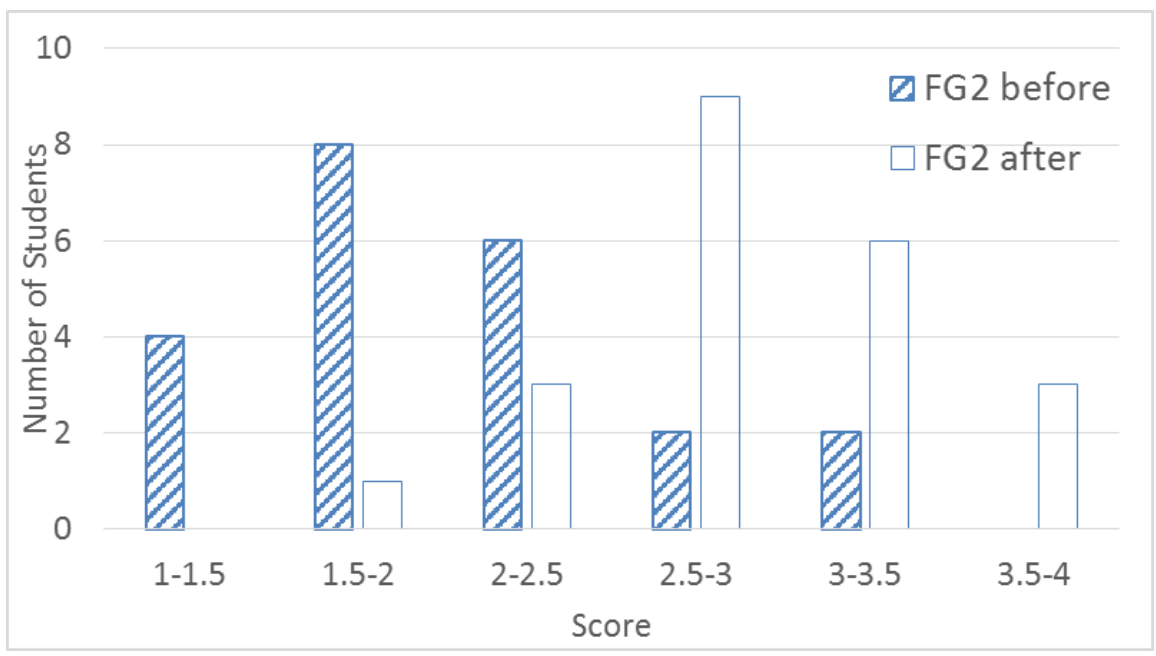

Figure 3. Test results of FG2

However, the results of FG2 that had time limitations and, consequently, experienced more stress, showed better results (Figure 4).

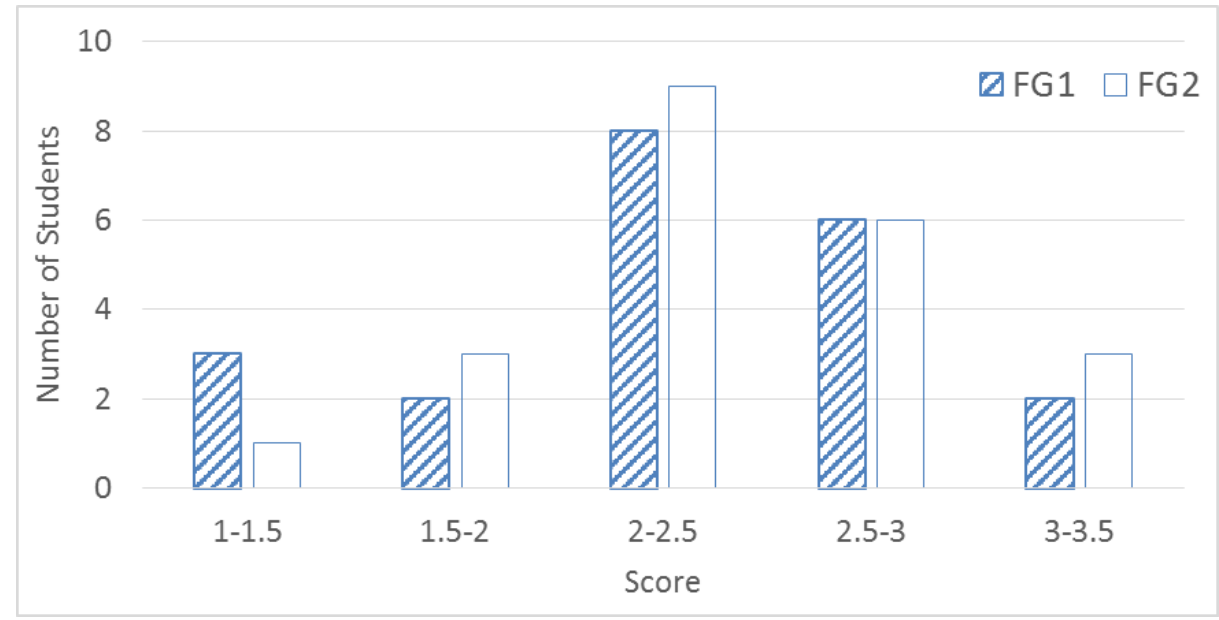

Figure 4. Test results: FG1 - focus group 1, FG2 - focus group 2

The average score of FG1 improved from 2.01 to 2.9, while FG2 participants scored 3.6 compared to the previous result -1.98 , proving not only the efficiency but also the need for blended learning integrated into the traditional classroom learning.

\section{Discussion}

It seems reasonable to aim the discussion at the problem under consideration in two directions. Namely, in terms of outlining the most important habits and skills in teaching bilateral interpreting and the most effective methods in developing the above-mentioned habits and skills.

As far as the first direction is concerned, we claim our full acceptance of Zinukova (2018) research regarding the fact that the formation and automation of the switching skills of students-interpreters will help optimise and speed up the professional development of future interpreters. This, in turn, requires the organised and purposeful practice of bilateral interpreting. Zinukova (2018) also notes that interpreters should "consider the development of switching skills as one of their main tasks" (p. 174). We also cannot but mention the research of Volodko (2017), who developed a methodology for the training of future consecutive interpreters in the field of scientific and technical translation (German and Ukrainian) based on the terminology of renewable energy sector.

As far as the second direction of the discussion is concerned, it seems quite reasonable to claim that it is blended learning that can provide the increasing volume of exercises aimed at developing the abovementioned habits and skills. 
Blended learning becomes an integral part of modern educational trends leading to inevitable changes in traditional perception of the educational teacher-centred process. We see blended learning courses for future bilateral interpreters as a compensator for the lack of classroom teaching time for bilateral interpreting. The results of this study go in line with Tarnopolsky (2012) work, proving that the learning process is more successful in case of the combination of traditional classroom course and web-based training.

The purpose of the pre-experimental stage (pre-test) was to find out the level of development of listening skills, code-switching, psychophysiological mechanisms development (memory capacity, reaction speed, concentration skills), and the ability to perform bilateral interpreting. The results of the postexperimental test (post-test) helped identify the level of formation of the ability to perform bilateral interpreting using interdisciplinary terminology. The criteria for evaluating the results of the pre- and posttest were the same as those for evaluating the results of the experiment.

The assessment system of the first two parts of the course employs Moodle automated assessment system, allowing almost all students' answers to be limited to "true/false" choice. Only for assessing the third part of the course (interpreting), the particular criteria, such as semantic adequacy and precision of interdisciplinary and narrow-domain terminology, were applied.

At the beginning of the experiment, the students attended an introductory lecture where the main concept of blended learning along with the detailed instructions was presented. The students also received by email the detailed instruction on the course objectives and general information, the time frames, activities, didactic and methodological tools as well as control and assessment techniques. An assessment system integrated in the Moodle platform allows students to check only their own grades and progress, whereas the teacher can see the detailed statistics for each student. At the beginning of every stage of the experiment, the students had face-to-face meetings with the teacher to get instructions regarding the course and get familiar with the structure and types of assignments. Regarding the fact the educational process in the blended learning mode involves independent extra-curricular work, the students had an opportunity to work remotely using suitable electronic means (personal computers, laptops, tablet or smartphones) choosing suitable time of the day for performing the tasks at their own pace. Such a training mode enhances their motivation to study. As was mentioned above, according to the Sloan Consortium definition (Elaine Allen, 2007), the blended courses are defined as having between 30 and 79 per cent of the course content delivered online. However, according to Tarnopolsky (2012), time distribution between a traditional classroom and online training within the blended learning course is an open question depending on the subject of study, purposes, students etc. This statement is in agreement with the results of current study, since the participants of our experiment experienced particular problems working with the blended learning course due to the lack of experience, tending to spend more time in the classroom. Given the existing problems, it was decided to blend the classroom and distance learning time in the ratio of 40 to $60 \%$. The course was designed for 20 hours. Initially, it was suggested to allocate 6 hours of classroom activities and 14 hours of independent students work, though later the ratio was changed to 8 to 12 hours respectively.

The findings of the present study also reveal that the blended learning course for future bilateral interpreters helps develop critical thinking and problem solving abilities, as well as accessing and analysing information, which is identified as a set of the competencies and skills, required by modern demand (Wagner, 2010).

\section{Conclusions}

The detailed analysis of scientific literature shows the modern information technologies, as well as blended learning in particular, become an integral part of modern educational tendencies both in Ukraine and abroad, offering a wide range of possibilities for students. The studies revealed the effectiveness of the blended learning mode within the bilateral interpreting course. Following the main objectives, the blended bilateral interpreting Moodle-based course was designed, including authentic materials and assessment criteria. Two focus groups participated in the experiment practicing bilateral interpreting using interdisciplinary terminology. Both groups, FG1 and FG2, had similar tasks and unlimited number of attempts, however, FG2 had limited time to perform the tasks imitating real bilateral interpreting process usually performed under stressful conditions. The obtained results showed that the participants of both groups developed their psychophysiological mechanisms, code-switching skills, and listening skills improving their interpreting skills, however, FG2 showed better results.

Through the entire experiment, the students were encouraged to participate actively both in classroom activities and in independent work within the Moodle-based platform, developing their analytical and critical thinking as well as problem solving, flexibility, and adaptability. 
Thus, the prospect of improving the efficiency as well as the quality of teaching future skilled interpreters is seen in integrating the blended learning course helping students practice and improve the skills of bilateral interpreting using interdisciplinary terminology at their own pace and in convenient conditions, giving future professionals significant professional benefits.

\section{References:}

Bonk, C. J. (2007). The handbook of blended learning: Global perspectives, local designs. San Francisco: Calif: Pfeiffer.

Brian North, E. P. (2016). Common European Framework of Reference for Languages: Learning, Teaching, Assessment Developing Illustrative Descriptors of Aspects of Mediation for the CEFR. Retrieved August 24, 2018, from $\mathrm{https}$ ://rm.coe.int/common-european-framework-of-reference-for-languages-learning-teaching/168073ff31

Buchbinder, V. A. (1986). Grundlagen der Methodik des Fremdsprachenunterrichts = Osnovy metodiki prepodavanija inostrannych jazykov. Leipzig: Verlag Enzyklopädie.

Dooly, M., \& Sadler, R. (2016, 02 01). Becoming little scientists: Technologically-enhanced project-based language learning. Language Learning \& Technology, pp. 54-78. https://doi.org/10125/44446

Elaine Allen, J. S. (2007, March). Blending In The Extent and Promise of Blended Education in the United States. Retrieved August 20, 2018, from Online Learning Survey: http://www.onlinelearningsurvey.com/reports/blending-in.pdf

Gmurman, V. (2004). Theory of probability and mathematical statistics. Moscow, Russia: Higher School.

Guryeyeva, L. (2016). Moodle-based course. Retrieved June 09, 2018, from New Education Technologies: http://vinec.net/moodle/

Hoyos, J. E. (2018, June 19). Error correction and repair moves in synchronous learning activities. International Journal of Educational Technology in Higher Education, 15(1). https://doi.org/10.1186/s41239-018-0105-2

Huber, J. M.-G. (2014). TASKs for Democracy: Developing Competences for Sustainable Democratic Societies. Strasbourg: Council of Europe Publishing.

Monteiro, K. (2014). An experimental study of corrective feedback during. Language Learning \& Technology, 18(3), 56-79. https://doi.org/10125/44384

Scott, C. L. (2016). THE FUTURES of LEARNING 2: What kind of learning for the 21st century? Paris: UNESCO Education Research and Foresight [ERF Working Papers Series, No. 14].

Spielberger, C. D. (1983). Manual for the State-Trait Anxiety Inventory. Palo Alto, CA: Consulting Psychologists Press.

STAI. (n.d.). The State-Trait Anxiety Inventory (STAI). Retrieved August 19, 2018, from American Psychological Association, http://www.apa.org/pi/about/publications/caregivers/practice-settings/assessment/tools/trait-state.aspx

Tarnopolsky, O. (2012). Constructivist Blended Learning Approach to Teaching English for Specific Purposes (A. Borowska, Ed.) London, Great Britain: Versita Ltd. Retrieved August 15, 2018, from https://web2.mlp.cz/koweb/00/04/24/15/13/constructivist_blended_learning_approach.pdf

Volodko, A. (2017). Metody ka navchannya majbutnix perekladachiv usnogo poslidovnogo naukovo-texnichnogo perekladu (nimecz 'ka ta ukrayins`ka movy`) [Methodology of Teaching Future Interpreters of Consecutive Scientific and Technical Interpreting]. PhD dissertation, Kyiv, Ukraine.

Wagner, T. (2010). Overcoming The Global Achievement Gap. Overcoming The Global Achievement Gap. Cambridge: Mass., Harvard University. Retrieved July 16, 2014, from www.aypf.org/documents/Wagner\%20Slides\%20\%20global\%20 achievement\%20gap\%20brief\%205-10.pdf

Ward, M. (2018, June 01). Qualitative research in less commonly taught and endangered language CALL. Language Learning \& Technology, 22(2), 116-132. https://doi.org/10125/44639

Welzer, T. D. (2018). World Congress on Medical Physics and Biomedical Engineering. Cultural aspects in technology-enhanced education (pp. 885-888). Singapore: Springer. https://doi.org/10.1007/978-981-10-9035-6_165

Zinukova, N. (2018). Metody`chna sy`stema navchannya studentiv magistratury` usnogo perekladu u zovnishn`oekonomichnij sferi (na materiali anglijs `koyi ta ukrayins`koy[Methodological System of Training Interpreting in Foreign Economic Field to Masters (English and Ukrainian)]. Doctoral dissertation, Kyiv, Ukraine. 